\title{
A GESTÃo DE PESSOAS COMO CONTRIBUIÇÃO À IMPLANTAÇÃO DA GESTÃO DE RISCOS. O CASO DA INDÚSTRIA DA CONSTRUÇÃO CIVIL
}

\section{PEOPLE MANAGEMENT AS CONTRIBUTION TO IMPLANTATION OF THE RISKS MANAGEMENT. THE CIVIL CONSTRUCTION INDUSTRY CASE}

\author{
Sergio Luiz Braga França \\ Engenheiro Civil \\ Universidade Federal Fluminense \\ Doutorando em Engenharia Civil
}

Rua Coronel Moreira César, 150/604, Icaraí, Niterói - RJ. CEP: 24230-062.

Tel: (21) 2711-7954; E-mail: sfranca@latec.uff.br

\author{
Marco Antonio Toze \\ Engenheiro Mecânico \\ Universidade Federal Fluminense \\ Mestrado em Sistemas de Gestão - LATEC
}

Rua José Ramos da Silva, 144, Praia 13 de Julho, Sergipe - Aracaju. CEP: 49020-200

Tel: (79) 246-2248; (79)9979-7312; E-mail: toze@ petrobras.com.br

\section{Osvaldo Luiz Gonçalves Quelhas \\ Engenheiro Civil \\ Universidade Federal Fluminense}

Mestrado Profissional em Sistemas de Gestão - LATEC/UFF

Rua Passos da Pátria, 156 - sala 329 - E, São Domingos, Niterói - RJ - CEP: 24210-240.

Tel: (21)2717 -6390; (21)2629-5616; E-mail: quelhas@latec.uff.br 


\title{
RESUMO
}

Este trabalho propõe identificar a gestão de pessoas como um facilitador para a gestão de riscos, através de análises de APRs (analise preliminar de risco) em atividades significantes, considerando os acidentes de trabalho, na indústria da construção civil. A relevância deste segmento implica na necessidade de criação e desenvolvimento de novas práticas de gestão objetivando minimizar os riscos relacionados à segurança e a saúde do trabalhador. Os autores apresentam as atividades com o maior índice de acidentes, e consolidam a importância da metodologia utilizada, estimulando as partes interessadas, principalmente a alta direção e os colaboradores, a perceberem e assumirem a responsabilidade frente aos problemas de segurança e saúde ocupacional e conscientizarem-se da necessidade de mudança na filosofia da produção. A partir da compreensão desses conceitos os autores apresentam estudo de caso em 02 atividades da construção civil, que historicamente apresentam o maior número de acidentes de trabalho, com o objetivo de evidenciar a importância desta pesquisa.

Palavras-chave: APRs; Gestão de pessoas; Gestão de riscos; Segurança e saúde ocupacional; Acidentes de trabalho.

\begin{abstract}
This work proposes to identify the management of people as a way of making easier for the risks management, through the analyze of ARPs (analyzes risk preliminary) in significant activities, considering the occupational accidents in the construction industry. The relevance of this segment implies in the creation and development of new management practices with the objective of minimizing risks related to the security and the health of the construction employees. The authors present the activities with the biggest amount of accidents, and consolidate the importance of the used methodology, stimulating the stakeholders, mainly the high direction and the collaborators, to perceive and to assume the responsibility front to the security problems and occupational health and to become conscious of the necessity of change in the philosophy of the production. From the understanding of these concepts the authors present study of case in 02 activities of the civil construction, that present the greater number of occupational accidents, with the objective to show the importance of this research.
\end{abstract}

Key-words: ARPs; Management of people; Risks management; Security and occupational health; Occupational accidents. 


\section{INTRODUÇÃO}

\subsection{Considerações Iniciais}

A Indústria da Construção Civil envolve elevado número de processos e produtos, representando um dos mais significativos setores econômicos para a maioria dos países, em especial para os países em desenvolvimento. No Brasil, estima-se que o construbusiness seja responsável por cerca de $15 \%$ do $\mathrm{PIB}$, empregando quase $50 \%$ dos trabalhadores e gerando mais de nove milhões de empregos diretos e indiretos (SOUZA, 1995).

Em função do grande volume de recursos financeiros e humanos que o setor movimenta, estratégias voltadas para o desenvolvimento de técnicas de gerenciamento de risco aplicado ao negócio tornam-se, portanto, questões fundamentais. Para reduzir o número de acidentes relacionados ao trabalho e manter a redução sistêmica destes, é necessário fazer da segurança um modo de viver. Precisa-se envolver as pessoas nas atividades diárias de forma consistente com a visão de uma cultura de segurança total.

Segundo Quelhas (2006), a cultura de segurança total (CST) é um dos mais recentes objetivos que os gestores de segurança buscam desenvolver dentro das organizações para atingir todos os empregados na busca da qualidade de vida no trabalho, através do compartilhamento de responsabilidades e uma preocupação ativa contínua com a segurança. Dentro das premissas da CST, a segurança não é caracterizada como uma prioridade e sim como um valor que está ligado a todas as outras prioridades, agregado a cada fase do desenvolvimento do produto.

A CST é uma adaptação do conceito de cultura organizacional, que segundo Schein (1992), é o conjunto de pressupostos básicos que um grupo inventou, descobriu ou desenvolveu ao aprender como lidar com os problemas de adaptação externa e integração interna e que funcionam bem o suficiente para serem considerados válidos e ensinados a novos membros como a forma de perceber, pensar e sentir em relação a esses problemas.

Nos últimos anos, vem sendo realizados grandes esforços no sentido de introduzir a gestão pela qualidade nas construtoras, porém as atividades da construção civil apresentam características singulares que dificultam a aplicabilidade das teorias modernas de qualidade. Merseguer, citado por Souza (1995), descreve algumas peculiaridades da construção, que 


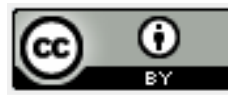

dificultam a transposição de conceito e ferramentas da qualidade no setor, são elas: a construção é uma indústria nômade; cria produtos únicos e seriados; é uma indústria muito tradicional com grande inércia às alterações; o grau de precisão com que se trabalha é, em geral, muito menor do que em outras indústrias; a construção, de maneira geral, realiza trabalhos sob intempéries. Por estes motivos, se a construtora não tiver o compromisso de padronizar os procedimentos e implantar programa de treinamento em gestão para todos os niveis da organização, a melhoria continua nos resultados dos processos dificilmente serão alcançados.

Os autores deste estudo identificam o comportamento de risco ou inseguros, o que as pessoas fazem, como a principal resposta para a questão sobre a causa dos acidentes. Segundo Schermerhorn (1999), o fator humano que podemos observar, registrar e em muitos casos até filmar e quantificar é o comportamento, ou seja, o conjunto de ações que o homem desempenha na interação com o mundo. É no âmbito dessa interação que ocorrem os acidentes e são geradas as condições para a ocorrência.

Mais de 70 anos de pesquisa e observação da teoria de Heinrich, desde 1930 até hoje, confirmam que os comportamentos de risco ou inseguros estão envolvidos na maioria dos acidentes (MASSERA, 2005). Muitos gestores falham em considerar os funcionários como os principais causadores dos acidentes, por isso a necessidade de mudança na cultura da segurança. Tal modo de pensar é um dos grandes obstáculos para o sucesso na implementação de novos modelos de gestão.

Almeida (2003), citando o trabalho de Reason, Carthey e de Leval (2001), demonstra que a visão descrita anteriormente leva a atribuição de culpa ao próprio acidentado, devido ao fato dos processos investigativos considerarem que algumas organizações são mais propensas a sofrer acidentes do que outras.

O enfoque apresentado por James Reason na sua obra é de que os acidentes ocorrem quando as defesas entre os perigos e os danos são perfuradas. A obra de Reason está levando as empresas a mudar de atitudes reativas (após o acidente) para ações proativas. Kletz (1993) por sua vez foca que as organizações devem se preocupar em mudar as situações com potencial de geração de acidentes e não tentar mudar as pessoas, ou seja, não adianta tentar mudar a natureza humana, mas sim incorporar nos projetos sistemas capazes de eliminar as oportunidades para o erro, mitigação e recuperação de erros. $\mathrm{O}$ autor sintetiza este ponto de vista da seguinte forma: "dizer que o acidente é devido à falha humana é tão útil quanto dizer que uma queda é devida à ação da gravidade". 


\subsection{Formulação da Situação Problema}

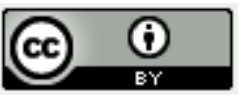

Segundo Massera (2005), a excelência em segurança e saúde do trabalho não pode ser alcançada apenas com programas, mas com mudanças contínuas de comportamento. A fundamentação teórica desta pesquisa apresenta a importância do envolvimento de toda a força de trabalho para o sucesso no gerenciamento de risco (GELLER, 1994).

Nos últimos 70 anos, as empresas têm focado quase que exclusivamente - Engenharia, Treinamento e Punição. Em grande parte, os profissionais de segurança assumiram este posicionamento. Agora é o momento de construir bloco de cultura, estratégia organizacional, liderança com desempenho e comportamento organizacional - que são as verdadeiras fontes de acidentes.

Complementando a realidade acima apresentada, os autores desta pesquisa identificam a necessidade de disseminar a importância da aplicação de ferramentas para o gerenciamento de risco na indústria da construção civil. Busca-se também identificar o nível da organização (estratégico, tático e operacional) que é responsável pelas atividades do diagrama do gerenciamento de risco.

Os empreendimentos deste segmento são únicos, utilizam mão de obra de baixa qualidade e, por menor que sejam, envolvem grandes quantidades de insumos. Estes fatores implicam na dificuldade para o gerenciamento do empreendimento e, principalmente, para o gerenciamento dos riscos destes empreendimentos.

\subsection{Estratégia da Pesquisa}

No que diz respeito à natureza trata-se de uma pesquisa aplicada devido ao fato de objetivar a geração de conceitos e modelos para aplicação prática, na indústria da construção civil, relacionada à gestão de pessoas e gerenciamento de risco.

É uma pesquisa qualitativa, pois as técnicas de coleta de dados utilizadas foram a observação participante dos autores nas atividades objeto deste estudo, as análises, comparações e interpretações de documentos, dados e informações disponíveis em literatura especializada. Os autores pesquisaram a fundamentação teórica em artigos, livros e dissertações, com o intuito de compreender os aspectos relacionados ao gerenciamento de risco na indústria da construção civil, bem como a gestão de pessoas aplicadas neste setor. 
Para tal, foram selecionados os principais autores destas 02 áreas do conhecimento.

A partir da compreensão desses conceitos, os autores analisam os resultados das APR's que foram elaboradas para as atividades da construção civil que representam o maior risco de acidentes e que estatisticamente apresentam o maior número de acidentes do trabalho e apresentam recomendações para redução de acidentes.

\section{REVISÃO DA LITERATURA}

\subsection{Gestão de Pessoas}

Em uma cultura de segurança, a segurança não é uma prioridade que pode ser mudada dependendo das exigências da situação; ao contrário, a segurança é um valor que está ligado a todas as outras prioridades, porém, isto é mais fácil ser dito do que ser feito. Geller (1994) afirma que a segurança deveria estar ligada, de modo consistente, a todos os aspectos do trabalho, quer se referindo à produtividade, qualidade, lucratividade ou eficiência.

A segurança deveria ser mais do que usar "equipamento de proteção pessoal", "desligar a força", "verificar possíveis riscos com o equipamento" e "manter a área de trabalho em ordem". A segurança deveria ser um valor que os empregados trariam a todos os cargos, apesar das prioridades ou exigências das tarefas. Deveria ser u ma regra tácita (norma social) que se seguisse independentemente de situações.

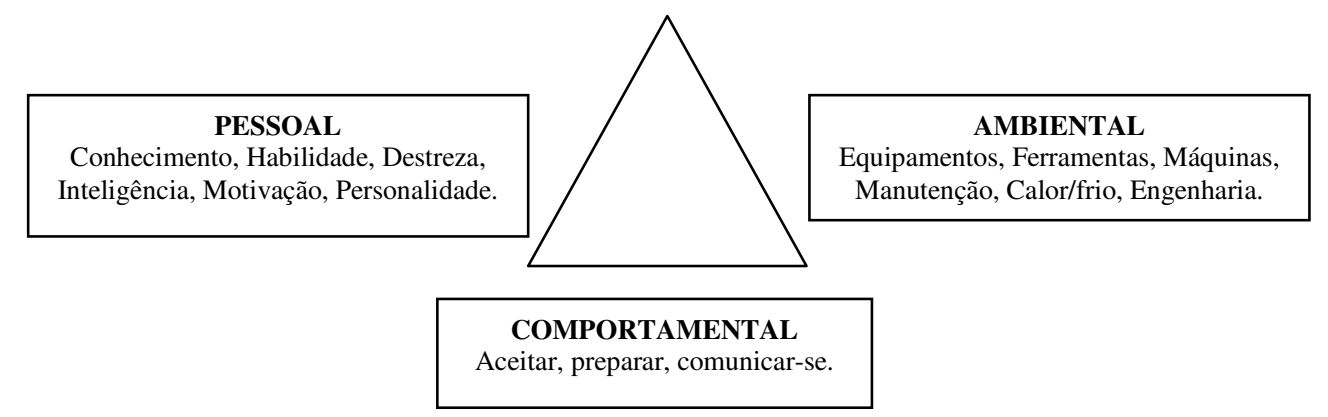

Figura 1: Fatores Responsáveis pela cultura de segurança

Fonte: Geller, 1994

Segundo Geller (1994), a cultura de segurança requer atenção contínua nos três domínios ilustrados na Figura 1: 1) fatores ambientais; 2) fatores pessoais; 3) fatores comportamentais. Esses fatores são dinâmicos e mudanças interativas em um fator podem, no final, causar impacto nos outros dois. Por exemplo, quando os empregados decidem agir com 
segurança, eles incorporam a atitude mental da segurança e tais comportamentos freqüentemente resultam em mudanças ambientais.

A melhor maneira de conquistar uma efetiva cultura de trabalho que contemple as disciplinas mencionadas acima é tratá-las de forma integrada. Este estudo visa evidenciar a necessidade de mudança na cultura de segurança do trabalho estabelecida hoje no mercado da construção civil. Segundo Souza (1995), o atual cenário deste setor apresenta-se passivo e reacionista. Para sua melhoria, é necessário promover uma cultura integrada baseada em atitudes prevencionistas e pró-ativas. Esta mudança poderá acontecer basicamente por uma efetiva troca de informação e experiências, assim como treinamentos, conscientização de conteúdo e aplicação prática na construção civil, à todos os níveis da organização (estratégico, tático e operacional), e que gere sensibilização, reciclagem e aperfeiçoamento de toda a mãode-obra.

A implantação da NR-18 ajudou muito a melhorar a qualidade das obras e também a qualidade de vida dos seus trabalhadores. De objetivo, ficou a diminuição drástica de acidentes no setor, principalmente no que se refere ao total de acidentes registrados entre os anos de 2002 e 2003, já que, no caso de óbitos, a redução não foi tão significativa.

Tabela 1: Perfil Nacional dos Acidentes na Indústria da Construção

\begin{tabular}{|l|l|l|l|l|l|}
\hline ANO & TOTAL & TÍPICO & TRAJETO & DOENÇS & ÓBITOS \\
\hline 1998 & 31.959 & 29.060 & 1.963 & 936 & 448 \\
\hline 1999 & 27.826 & 24.950 & 2.008 & 868 & 407 \\
\hline 2000 & 25.536 & 22.637 & 2.112 & 787 & 325 \\
\hline 2001 & 25.446 & 22.557 & 2.154 & 735 & 337 \\
\hline 2002 & 28.484 & 25.029 & 2.532 & 923 & 375 \\
\hline 2003 & 21.972 & 19.093 & 2.187 & 692 & 310 \\
\hline
\end{tabular}

Fonte: Ministério da Previdência e Assistência Social (MPAS)

Apesar da diminuição dos índices ao longo dos anos, os números de acidentes, principalmente de óbitos ainda são expressivos na indústria da construção, o que gera a necessidade de uma atividade gerencial mais atuante e com foco preventivo em suas ações.

\subsection{Gerenciamento de Riscos}

Segundo Geller (1994), os gestores têm cometido um grande equívoco, quando analisam a segurança do trabalho separadamente dos aspectos administrativo, econômico, ambientas e social das empresas. Atualmente, é notória a falta de compreensão por parte dos 


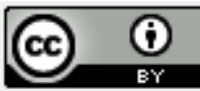

executivos, dos custos dos acidentes e dos outros acontecimentos que ocasionam perdas, comprometendo a imagem da empresa e muitas vezes a sua sobrevivência. Poucos são os executivos que compreendem que os mesmos fatores que ocasionam acidentes estão também criando perdas de eficiência, bem como problemas de qualidade, custo e de imagem da empresa (SOUZA, 2000). É necessária uma boa política de prevenção de acidentes, adequada para atuar, corrigir e prevenir os pequenos acidentes e os incidentes.

Observando os dados da Fundacentro, o número de acidentes que ocorre anualmente na indústria da construção civil é inaceitável. Segundo Souza (2000), não podemos aceitar empresas que relutam em adotar políticas e práticas prevencionistas. O comportamento das pessoas deve passar de reativo para pró-ativo. As ações devem ser de antecipação e não mais de correção.

\subsubsection{Diagrama de Gerenciamento de Risco e seus Requisitos}

Segundo a AS/NZS 4360, o diagrama apresentado a seguir representa o conceito do gerenciamento de risco que é proteger o patrimônio da empresa, através da identificação dos riscos, sejam relacionados à propriedade, ao pessoal, aos processos, ao produto, ao equipamento ou ao ambiente. Após a identificação, os riscos são analisados em termos de severidade e freqüência e avaliados quanto à categoria do risco. A alta administração trata o risco conforme a política de risco da empresa, com o objetivo de reduzir, evitar, assumir ou repassar o risco a segurador. Com base nestas informações, a empresa elabora ou atualiza o Programa de Prevenção e Controle de Perdas. Este Programa busca maximizar os resultados da empresa, otimizando o uso de recursos humanos, materiais ou financeiros.

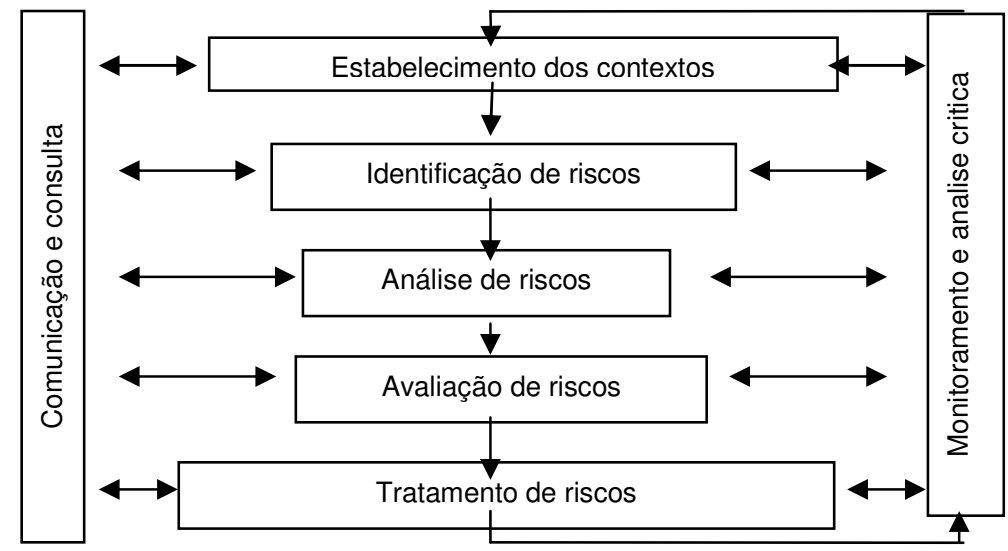

Figura 2: Diagrama de Gerenciamento de Risco

Fonte: AS/NZS 4360 


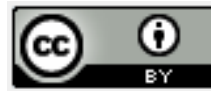

A alta administração da organização, junto com as partes interessadas, deve desenvolver uma política organizacional de gestão de risco e um mecanismo de suporte, a fim de fornecer uma estrutura para a condução de um programa de gestão de riscos mais detalhado. Segundo a AS/NZS, os requisitos para a gestão de riscos são: política de gestão de riscos, responsabilidades e autoridades, recursos, programa de implementação e analise crítica pela direção.

A direção da organização deve assegurar que seja realizada uma análise crítica do sistema de gestão de riscos a intervalos especificados, que permitam garantir sua contínua adequação e eficácia em atender os requisitos e as normas de gerenciamento de riscos, como por exemplo, a AS/NZS 4360. A gestão de risco é um processo de melhoria contínua que a cada ciclo deve ser atualizado conforme os resultados do monitoramento e análise crítica.

Atualmente, as leis, as normas e a própria sociedade exige que as organizações atuem de forma sustentável. Uma medida básica de comprometimento da alta direção com esta questão é um bom programa de comunicação e consulta as partes interessadas envolvidas internas e externas, conforme apropriado, em cada etapa do processo de gestão de riscos e em relação ao processo como um todo.

Para que as mudanças ocorram, segundo Laino \& Rodrigues (2003), é necessário que as empresas identifiquem a cultura de seus colaboradores, ou seja, seus principais valores e certezas compartilhadas, implementando as mudanças capazes de apoiar as novas estratégias adotadas. Ainda segundo os autores, o objetivo do estudo da cultura organizacional é minimizar a dificuldade na adoção de novas estratégias, tecnologias e no implemento de novos projetos. A partir do entendimento da cultura organizacional, busca-se maior comprometimento dos colaboradores no atingimento das metas estabelecidas pela organização.

\subsection{Análise Preliminar de Riscos (APR)}

Este método é utilizado para a análise inicial dos riscos e caracteriza-se por apresentar informações qualitativas. A sua aplicação é ideal na fase de projeto ou de desenvolvimento de qualquer novo processo, produto ou sistema (SOUZA, 2000).

A APR tem como objetivo determinar os riscos e as medidas preventivas antes da fase operacional. A metodologia aplicada é a revisão geral de aspectos de segurança, através de 
um formato padrão, levantando as causas e efeitos de cada risco, medidas e prevenção ou correção e categorização dos riscos. Este método facilita a priorização das ações preventivas e corretivas e permite revisões nos projetos em tempo hábil, proporcionando maior segurança.

Além disso, a APR permite previamente estimar qualitativamente o risco associado a cada sequiência de eventos, a partir da estimativa da frequiência e da severidade da sua ocorrência. A APR avalia qualitativamente a severidade e a freqüência de ocorrência dos perigos identificados. As medidas utilizadas devem refletir as necessidades e a natureza da organização e da atividade em estudo. Esta avaliação deve ser feita por um especialista. Estes dois fatores são os responsáveis pela classificação do risco (Tabela 2).

Apresenta-se na Tabela 2 um modelo de matriz de analise qualitativa de riscos, quanto ao nível do risco. O número de categorias deve refletir as necessidades do estudo.

Tabela 2: Matriz de Análise Qualitativa de Risco - Nível de Risco

\begin{tabular}{|c|c|c|c|c|c|}
\hline \multirow[t]{2}{*}{ Frequiência } & \multicolumn{5}{|c|}{ Severidade } \\
\hline & $\mathbf{I}$ & II & III & IV & $\mathbf{V}$ \\
\hline $\mathbf{A}$ & 2 & 2 & 1 & 1 & 1 \\
\hline B & 3 & 2 & 2 & 1 & 1 \\
\hline $\mathrm{C}$ & 4 & 3 & 2 & 1 & 1 \\
\hline D & 4 & 4 & 3 & 2 & 1 \\
\hline $\mathbf{E}$ & 4 & 4 & 3 & 2 & 2 \\
\hline
\end{tabular}

Fonte: AS/NZS 4360 Adaptado pelos autores.

A Tabela 3 apresenta a definição das categorias do risco que são identificadas conforme matriz de análise qualitativa de risco que confronta o nível de freqüência $\mathrm{x}$ o nível de severidade.

Tabela 3: Definição das Categorias do Risco

\begin{tabular}{|l|}
\hline Categoria do Risco \\
\hline 1 - Risco extremo, necessária uma ação imediata \\
\hline 2 - Risco alto, necessária a atenção da alta administração \\
\hline 3 - Risco moderado, a responsabilidade da alta administração deve ser especificada \\
\hline 4 - Risco baixo, gerenciando por procedimentos de rotina \\
\hline
\end{tabular}

Fonte: AS/NZS 4360 Adaptado pelos autores.

A classificação do risco é uma informação muito importante para a análise preliminar do risco, pois indicará a ordem de prioridade que a organização deverá alocar recursos, seja 


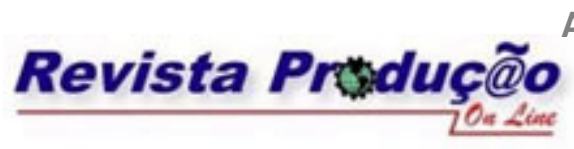

Associação Brasileira de Engenharia de Produção - ABEPHQ

Universidade Federal de Santa Catarina - UFSC

www.producaoonline.org.br

ISSN 1676 - 1901 / Vol. VIII/ Num. IV/ 2008

pessoal ou financeiro, e as medidas preventivas.

\section{ANÁLISE PRELIMINAR DE RISCO (APR) EM ATIVIDADES DA INDÚSTRIA DA CONSTRUÇÃO CIVIL}

\subsection{Considerações Iniciais}

Neste capítulo, a partir da experiência dos autores, analisam-se os resultados das APR's que foram elaboradas pelos autores para as seguintes atividades: planos elevados e central de carpintaria. A escolha foi baseada nas atividades mais significantes na Construção Civil quanto ao risco de acidentes utilizando dados levantados pela DRT-RJ e a Fundacentro.

\subsection{Identificação das Atividades para Elaboração da APR}

3.2.1. DRT-RJ - Delegacia Regional do Trabalho do Rio de Janeiro: Situação de Grave e Iminente Risco

Com objetivo de elevar o padrão das condições de trabalho nos Canteiros de Obras no Estado do Rio de Janeiro, tendo como foco a preservação da dignidade e da integridade física do trabalhador, foi anunciado na sede da DRT-RJ, o Programa Especial de Fiscalização na Construção Civil.

Um Termo de Notificação Padrão foi elaborado pela SEGUR - Seção de Segurança e Saúde do Trabalhador e SFISC - Seção de Fiscalização do Trabalho, para que uma equipe da DRT-RJ desenvolvesse as ações de fiscalização nos canteiros de obras, envolvendo a Construtora principal, as sub-empreiteiras e prestadoras de serviços.

As Ações Fiscais determinaram a realização das mesas de entendimentos ou penalidades que compreenderam autuação, interdição ou embargo em "Situações de Grave e Iminente Risco" quanto a serra circular (carpintaria), proteção contra quedas de altura (planos elevados), andaimes, instalações elétricas, movimentação e transporte de materiais e pessoas. 


\subsubsection{Dados Estatísticos da Fundacentro}

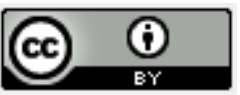

Neste item, apresentam-se os dados estatísticos dos acidentes de trabalho que foram divulgados pela Fundacentro. Os autores apresentam nas tabelas abaixo as funções pertinentes às atividades que serão analisadas nesta pesquisa: planos elevados, instalações elétricas temporárias em canteiros de obras e central de carpintaria.

Tabela 4: Distribuição do Número de Acidentes do Trabalho na Indústria da Construção, segundo a função - Brasil 1998 e 1999.

\begin{tabular}{|l|l|l|l|l|}
\hline Função & $\mathbf{1 9 9 8}$ & $\mathbf{\%}$ & $\mathbf{1 9 9 9}$ & $\mathbf{\%}$ \\
\hline Carpinteiro & 187 & 8.93 & 277 & 15.76 \\
\hline Operador de Equipamento & 142 & 6.79 & 72 & 4.10 \\
\hline Pedreiro / Estucador & 132 & 6.30 & 151 & 8.60 \\
\hline Servente & 491 & 23.46 & 386 & 21.97 \\
\hline
\end{tabular}

Fonte: Fundacentro (2002).

Os dados estatísticos apresentados na tabela acima evidenciam que as atividades do carpinteiro, do operador de equipamentos, do pedreiro / estucador e do servente são as que mais representam acidentes do trabalho na indústria da construção civil.

Tabela 5: Distribuição do Número de Acidentes do Trabalho na Indústria da Construção, segundo a natureza do acidente - Brasil 1998 e 1999.

\begin{tabular}{|l|l|l|l|l|}
\hline Função & $\mathbf{1 9 9 8}$ & \% & $\mathbf{1 9 9 9}$ & \% \\
\hline Aprisionamento ou prensagem & 213 & 10.17 & 212 & 12.07 \\
\hline Corpo estranho & 104 & 4.97 & 62 & 3.53 \\
\hline Impacto contra & 270 & 12.90 & 236 & 13.43 \\
\hline Impacto sofrido & 573 & 27.37 & 460 & 26.18 \\
\hline Queda com diferença de nível & 234 & 11.18 & 177 & 10.07 \\
\hline Reação do corpo e seus movimentos & 161 & 7.69 & 106 & 6.03 \\
\hline
\end{tabular}

Fonte: Fundacentro (2002)

Os dados estatísticos da tabela acima estão relacionados com as funções destacadas na tabela 4 reforçando a representatividade das atividades em que carpinteiros, operadores de equipamentos, pedreiro, estucador e serventes estão envolvidos.

\subsection{Elaboração da Análise Preliminar de Risco}

A construção civil, por suas características peculiares, tem uma condição de insegurança inerente a sua própria atividade, assim como atos inseguros que a maioria dos líderes, sejam engenheiros, mestres-de-obras e encarregados, assume em suas atividades 


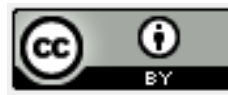

diárias, sem avaliarem os riscos das atividades que desenvolvem, expondo a si próprios e a seus colegas de trabalho a riscos desnecessários. Pode-se citar, como atos inseguros, uma situação em que um profissional não seguiu um procedimento pré-definido e, como conseqüência, ocorreu uma falha. Este modo de análise considera que os erros acontecem devido à falta de atenção, baixa motivação, negligência ou desvio de conduta

As atividades ocorrem, na grande maioria, sem uma análise, sem um estudo prévio do que será executado e quando essa análise ocorre, invariavelmente, a segurança é relegado a um segundo plano. Em resumo, preocupa-se com a madeira, a barra de aço, com a necessidade de se ter um ponto de energia na frente de obra, com a urgência de se estar a 5 metros de altura para terminar a forma de um pilar, mas as condições de segurança, que envolvem desde uma verificação das condições e estado do insumo utilizado, passando pelas ferramentas adequadas para um serviço específico, até o adequado dimensionamento de um EPC ou um EPI, que são pouco levadas em consideração.

Segue abaixo a analise das atividades e dos resultados das APR's que foram elaboradas para as atividades da construção civil.

\subsubsection{Planos Elevados}

$\mathrm{Na}$ atividade da indústria da construção civil existem inúmeras situações de elevado risco, inerentes a própria atividade. A falta de proteção em situações de risco de quedas de altura constitui-se na causa principal do elevado número de acidentes fatais, vitimando centenas de trabalhadores a cada ano, como indicam as estatísticas no Brasil.

$\mathrm{Na}$ indústria da construção civil, destacam-se as atividades a seguir, as quais envolvem riscos de queda de altura: partes periféricas de lajes, aberturas de piso, vãos de acesso às caixas de elevadores, vãos de escadarias ou rampas, serviços executados em sacadas e / ou varandas, construção e manutenção de telhados e / ou coberturas, montagem e desmontagem de andaimes fachadeiros, montagem e desmontagem de torres de elevadores de obras, trabalhos em andaimes suspensos, montagem de elementos estruturais (pré-moldados, metálicos), trabalhos em confecção de fôrmas, ferragens e concretagem de estruturas e lajes, manutenção de fachadas de edifícios e inspeção e manutenção de chaminés.

Os riscos de quedas de trabalhadores e / ou projeções de materiais podem ser neutralizados por meio de Medidas de Proteção Coletiva e / ou Medidas de proteção individual. Os EPI's e EPC's recomendados em geral são: uniforme completo de mangas compridas, luva de vaqueta mista, botina de couro, cinto de segurança tipo pára-quedista com 
dois talabartes, isolamento de área de trabalho com fita zebrada, escada de acesso presa ao quadro horizontal, assoalho de madeira completo e travado e guarda corpo.

Apresenta-se abaixo a Analise Preliminar de Risco:

Tabela 6: Análise Preliminar de Risco para Planos Elevados

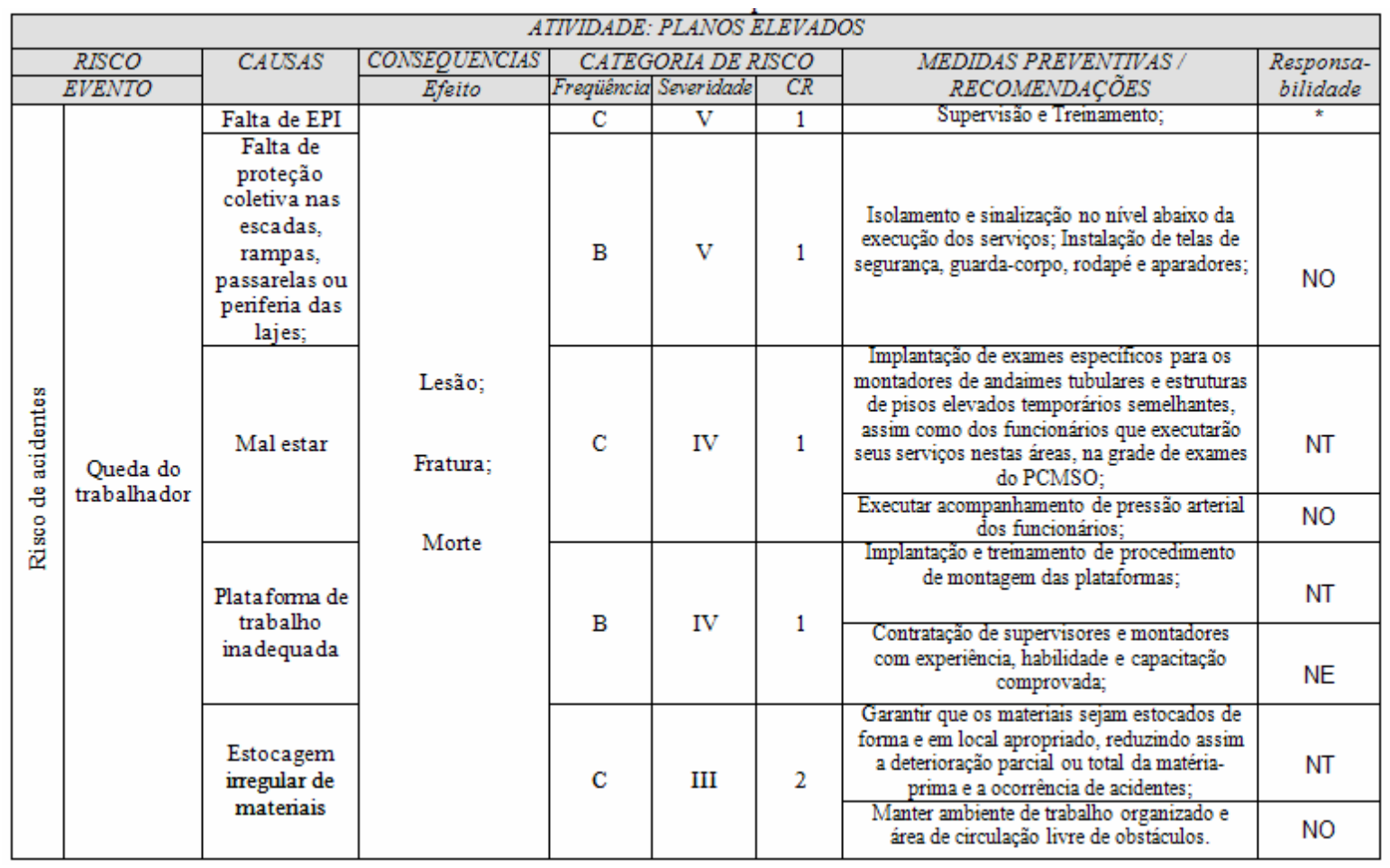

* Nível Estratégico (NE) - Assegurar; Nível Tático (NT) - Garantir; Nível Operacional (NO)- Executar Fonte: os autores

\subsubsection{Central de Carpintaria}

Os trabalhos na central de carpintaria e as atividades executadas pelos carpinteiros de uma forma geral na indústria da construção civil são a fabricação de painéis para formas, a montagem e a desmontagem das mesmas, formas essas utilizadas para estruturas de concreto como pilares, lajes, vigas paredes e muros, desde concepções simples como uma simples cisterna, até estruturas arrojadas como obras de arte especiais como a Ponte Rio-Niterói, o Museu de arte contemporânea de Niterói, etc.

Os EPI's básicos de um carpinteiro são: capacete, luva, bota de couro e óculos de segurança. No caso de operadores de serra circular, outros EPI's se fazem necessários: avental de raspa, protetor facial, protetor auricular tipo concha e máscara descartável. Os EPC's considerados mínimos são: proteção das lâmpadas, cutelo divisor, coifa de proteção, caixa de coleta de serragem e extintor de incêndio tipo água pressurizada e CO2 ou PQS. 


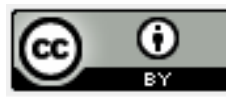

O potencial de acidentes ou perdas é muito grande em uma central de carpintaria principalmente com relação a quedas de mesmo nível, risco de incêndio, ruído, lesão e corte dos membros superiores, projeção de partículas, postura inadequada, uso de ferramentas inadequadas e defeituosas e levantamento e transporte manual de peso. As condições mínimas que uma central de carpintaria deve ter envolvem uma instalação com cobertura apropriada, no caso de risco de queda de objetos nos trabalhadores, uma sinalização clara com respeito à correta utilização dos EPI's relacionados às atividades de uma central de carpintaria, sinalização de que é proibido fumar na central, iluminação adequada, piso firme, nivelado e antiderrapante, um extintor de incêndio tipo $\mathrm{CO} 2$, próximo à mesa da serra circular, assim como um estudo prévio do lay out e da melhor localização desta central de carpintaria, no intuito de preservar os funcionários das demais instalações com relação ao ruído, evitando assim a obrigatoriedade de que esses outros funcionários usem EPI's devido a central de carpintaria.

Apresenta-se abaixo a Analise Preliminar de Risco.

Tabela 7: Análise Preliminar de Risco para Central de Carpintaria

\begin{tabular}{|c|c|c|c|c|c|c|c|c|}
\hline \multicolumn{9}{|c|}{ ATIVIDADE: CENTRAL DE CARPINTARIA } \\
\hline & RISCO & \multirow{2}{*}{ CAUSAS } & \multirow{2}{*}{\begin{tabular}{|c|} 
CONSEQUENCIAS \\
Efeito \\
\end{tabular}} & \multicolumn{3}{|c|}{ CATEGORIA DE RISCO } & \multirow{2}{*}{$\begin{array}{c}\text { MEDIDAS PREVENTIVAS/ } \\
\text { RECOMENDAÇÕES }\end{array}$} & \multirow{2}{*}{$\begin{array}{l}\text { Responsabi- } \\
\text { lidade }\end{array}$} \\
\hline & EVENTO & & & Freqüência & Severidade & $C R$ & & \\
\hline \multirow{14}{*}{ 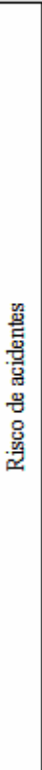 } & \multirow{8}{*}{$\begin{array}{c}\text { Alta } \\
\text { voltagem }\end{array}$} & \multirow{8}{*}{$\begin{array}{l}\text { Falta de } \\
\text { aterramento }\end{array}$} & \multirow{8}{*}{$\begin{array}{l}\text { Choque elétrico; } \\
\text { Queimadura; } \\
\text { Morte }\end{array}$} & \multirow{8}{*}{$\mathrm{C}$} & \multirow{8}{*}{$\mathrm{V}$} & \multirow{8}{*}{1} & Supervisão e Treinamento; & * \\
\hline & & & & & & & $\begin{array}{l}\text { Implantação de procedimento de revisão } \\
\text { perídica de todas as instalações elétricas; }\end{array}$ & NT \\
\hline & & & & & & & Programa de manutenção preventiva; & * \\
\hline & & & & & & & $\begin{array}{c}\text { Realização dos serviços em circuitos } \\
\text { desenergizados e por trabalhador qualificado; }\end{array}$ & NO \\
\hline & & & & & & & $\begin{array}{c}\text { Utilização de materiais especificados no } \\
\text { projeto; }\end{array}$ & NO \\
\hline & & & & & & & $\begin{array}{l}\text { Execução de checklists nas instalações } \\
\text { elétricas; }\end{array}$ & NO \\
\hline & & & & & & & $\begin{array}{c}\text { Estruturação dos serviços de primeiros } \\
\text { socorros; }\end{array}$ & NT \\
\hline & & & & & & & Aterramento apropriado; & NO \\
\hline & \multirow{4}{*}{$\begin{array}{l}\text { Queda do } \\
\text { mesmo nivel }\end{array}$} & \multirow{4}{*}{$\begin{array}{c}\text { Piso } \\
\text { desnivelado ou } \\
\text { escorregadio }\end{array}$} & \multirow{4}{*}{$\begin{array}{l}\text { Lesão; } \\
\text { Fratura }\end{array}$} & \multirow{4}{*}{ B } & \multirow{4}{*}{ III } & \multirow{4}{*}{2} & Supervisão e Treinamento; & * \\
\hline & & & & & & & $\begin{array}{l}\text { Manter ambiente de trabalho organizado e } \\
\text { área de circulação livre de obstáculos; }\end{array}$ & NO \\
\hline & & & & & & & $\begin{array}{l}\text { Providenciar piso resistente, nivelado e } \\
\text { antiderrapante; }\end{array}$ & NO \\
\hline & & & & & & & Manter carpintaria limpa e organizada; & $\mathrm{NO}$ \\
\hline & \multirow[b]{2}{*}{$\begin{array}{l}\text { Projeção de } \\
\text { particulas }\end{array}$} & \multirow[b]{2}{*}{$\begin{array}{l}\text { Equipamento } \\
\text { sem coifa }\end{array}$} & \multirow[b]{2}{*}{ Lesão } & \multirow[b]{2}{*}{$\mathrm{C}$} & \multirow[b]{2}{*}{ III } & \multirow[b]{2}{*}{2} & Supervisão e Treinamento; & ${ }^{*}$ \\
\hline & & & & & & & $\begin{array}{l}\text { Selecionar e inspecionar as pranchas a serem } \\
\text { cortadas livres de resto de concreto, pregos, } \\
\text { nós duros, vazios, arames, bem como outro } \\
\text { objeto que possa travar ou provocar o } \\
\text { deslizamento da madeira a ser trabalhada. }\end{array}$ & NO \\
\hline
\end{tabular}

* Nível Estratégico (NE) - Assegurar; Nível Tático (NT) - Garantir; Nível Operacional (NO)- Executar Fonte: os autores 


\subsection{Análise Crítica}

Após analise das APR's, os autores constatam que para o sucesso de um plano de segurança é necessário a sinergia de todos os níveis organizacionais. Conforme a tabela 8, as medidas preventivas / recomendações das APR's são fundamentalmente pertinentes as atividades de execução no canteiro de obra, sob responsabilidade do nível operacional, evidenciando a importância deste nível para a implementação eficaz do plano de segurança. Constata-se também que é necessário um alto grau de comprometimento dos níveis estratégicos e táticos, pois estes são os responsáveis respectivamente por assegurar e garantir as práticas de segurança. Estatisticamente, relacionam-se as medidas preventivas / recomendações das APR's com os níveis organizacionais e os resultados comprovam estas conclusões (FRANÇA, 2005).

Tabela 8: Análise das APR's - Percentual de Responsabilidade dos Níveis Organizacionais

\begin{tabular}{|l|l|l|}
\hline Nível & Função / cargo & Percentual de Responsabilidade \\
\hline Estratégico & Diretoria & $1,7 \%$ \\
\hline Tático & Gerentes e Engenheiros & $25,6 \%$ \\
\hline Operacional & $\begin{array}{l}\text { Mestres, encarregados e mão de obra } \\
\text { operacional }\end{array}$ & $48,8 \%$ \\
\hline Todos & Todos & $24 \%$ \\
\hline
\end{tabular}

Fonte: os autores

A utilização da ferramenta APR nas atividades indicadas anteriormente, revela-se uma contribuição importante para a gestão de segurança do trabalho na indústria da construção civil, a partir do momento em que ela é vista como um elemento fundamental para um plano de segurança eficaz. Entretanto, o grande problema é que na prática, a realidade deste setor continua com o discurso da improvisação e a atitude de auto-suficiência, perante os perigos e riscos. A alta administração que deveria dar o exemplo para a força de trabalho, ainda preza pelo objetivo de produzir a qualquer custo. Por este motivo, os autores buscam contribuir com uma proposta de plano de segurança que tem como objetivo de identificar o grau de comprometimento de todos os níveis da organização e a sinergia entre eles. Muitos gestores falham em considerar os funcionários como os principais causadores dos acidentes, por isso a necessidade de mudança na cultura da segurança. Tal modo de pensar é o grande obstáculo para o sucesso na implementação de novos modelos de gestão. 


\section{CONCLUSÃO E RECOMENDAÇÕES PARA FUTURAS PESQUISAS}

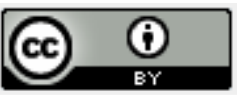

O principal pré-requisito para a efetividade de qualquer sistema de gestão de segurança do trabalho é o comprometimento de todos, desde a alta administração até os operários.

Porém, a indústria da construção civil preserva, em grande parte das empresas, o gerenciamento tradicional, não participativo. Por este motivo, para o desenvolvimento e implementação de um sistema de gestão de segurança do trabalho realmente efetivo, é necessária a sensibilização da alta administração e o foco na prevenção.

Com intuito de promover melhorias nesta área, as legislações de segurança têm sido aprimoradas, porém a constância dos altos índices de acidentes nos últimos anos reflete a necessidade de mudança da abordagem pontual para uma abordagem sistêmica. Desta forma, passa-se a ter uma visão macro da organização, integrando todos os níveis hierárquicos de forma a propiciar o desenvolvimento e a consecução de um objetivo maior, garantir a saúde e a segurança de todos os elementos da organização.

Isoladamente as medidas preventivas recomendadas nas APR's por si só não promovem a melhoria no processo produtivo quanto a redução dos riscos de acidentes, por se tratarem de ações pontuais e não sistêmicas e em momento inadequado do seu uso. Os autores ratificam a necessidade de desenvolvimento da APR antes da elaboração do plano de segurança, caso contrário, a função prevencionista de um plano não estará sendo atendida.

A aplicação desta ferramenta na fase de projeto ou de desenvolvimento de qualquer novo processo, produto ou sistema na indústria da construção civil é fundamental para que se cumpra o objetivo de determinar a categoria dos riscos e as medidas preventivas antes da fase operacional, permitindo revisões de projeto em tempo hábil no sentido de promover maior segurança para o trabalhador, o meio ambiente e o patrimônio da organização. Com o foco na prevenção, a análise preliminar de risco poderá apresentar os seguintes benefícios para a indústria da construção civil: reduzir a freqüência e gravidade de eventos indesejados no canteiro de obra; adequar o seguro aos reais riscos dos empreendimentos; reduzir e / ou eliminar as indenizações / multas provenientes de danos ao meio ambiente, identificar necessidades de treinamentos; detectar as deficiências e otimizar os gastos com manutenção; preservar a imagem da construtora; manter o ambiente de trabalho adequado quanto à segurança e priorizar as tomadas de decisões dos investimentos necessários em prevenção. 


\section{REFERÊNCIAS}

ALMEIDA, I. M. (ORG.) Caminhos da análise de acidentes do trabalho. Brasília: MTE, SIT, 2003

BRASIL. Ministério do Trabalho. Norma Regulamentadora $n^{\circ}$. 18. Condições e Meio Ambiente de Trabalho na Indústria da Construção. Brasília: NR-18, 7 de julho de 1995.

CARDELLA, B. Segurança no trabalho e prevenção de acidentes. Uma abordagem holística: segurança integrada à missão organizacional com produtividade, qualidade, preservação ambiental e desenvolvimento de pessoas. São Paulo: Atlas, 1999.

CHIAVEnAto, Idalberto. Gerenciando Pessoas: O passo decisivo para a administração participativa. São Paulo: Makron Books, 1992.

CRUZ, S. M. S. Gestão de segurança e saúde ocupacional nas empresas de construção civil. 1998. Dissertação (Mestrado em Engenharia de Produção) - Universidade Federal de Santa Catarina, Florianópolis, 1998.

FRANÇA, S. L. B.; MENDES, C. C.; MOREIRA, L. C. P.; CERBINO, R. Análise preliminar de risco como fator crítico de sucesso para estruturação de um plano de segurança da construção civil. 2005. Monografia (Especialização em Engenharia de Segurança do Trabalho) - LATEC, Universidade Federal Fluminense, Niterói, 2005.

GELLER, E. SCOTT. Ten principles for achieving a total safety culture. Professional Safety. American Society of Safety Engineers. 1994.

HALL, J. Gestão da segurança total na construção civil: um instrumento de otimização da estratégia de produção com o objetivo de obtenção de vantagens competitivas: subsetor edificações. 2001. Dissertação (Mestrado em Engenharia Civil) - Universidade Federal Fluminense, Niterói, 2001.

Kletz TA. O que houve de errado? São Paulo: Makron Books; 1993

KRAUSE, T. R. Segurança e qualidade: Os dois lados da mesma moeda. São Paulo: Quality Progress, 1994.

LAINO, Aparecida de Souza \& RODRIGUES y RODRIGUES, Martius V. O diálogo da cultura organizacional através do modelo dos valores contrastantes: um estudo de caso. In: SIMPEP, 11. Anais. Bauru, SP. 2004

MASSERA, C. Soluções em comportamento, prevenção de acidentes e ergonomia. Revista Proteção, Novo Hamburgo - RS, 2005.

OHSAS 18 001: Occupational health and safety management systems -Specification. 1999, $13 \mathrm{p}$. 
QUELHAS, Adriane Domingues. Desenvolvimento de uma Cultura de Segurança Total: Um Estudo de Caso em Indústria Automotiva na Região Sul Fluminense. Dissertação de Mestrado em Sistemas de Gestão. Universidade Federal Fluminense. Niterói. 2006.

REASON, J. Combating omission errors through task analysis and good reminders. Quality Safety Health Care; v. 11, p. 40-44, 2002.

REASON, J. Beyond the organizational accident: the need for "error wisdom" on the frontline. Quality Safety Health Care, v. 13, p. 28-33, 2004.

SCHEIN, E. H. Organizational Culture and Leadership. San Francisco. Jossy-Bass, 1992.

SMALLWOOD, John J. The influence of management on occupational health and safety. in Implementation of Safety and Health on Construction Sites - Proceedings of the first international conference of CIB working commission W99. Lisboa. Portugal. setembro de 1996.

SOUZA, Carlos Roberto Coutinho de. Análise e gerenciamento de riscos em processos industriais. Apostila do Curso de Especialização em Engenharia de Segurança do Trabalho. Universidade Federal Fluminense. 2000.

SOUZA, R. de; MEKEBEIAN, G.; SILVA, M.A C; LEITÃO, A C.M.T.; SANTOS, M.M. Sistemas de gestão da qualidade para empresas construtoras. São Paulo: Sinduscon/SP, 1994.

SOUZA, R, et al. Sistema de gestão da qualidade para empresas construtoras. São Paulo: Pini, 1995.

YIN, R. Estudo de caso: planejamento e métodos. $3^{\text {a }}$ Ed. São Paulo: Bookman, 2004.b 